\title{
On the Subversive Nature of Historical Materials
}

\author{
LIU DONG, TSINGHUA UNIVERSITY, CHINA
}

This headnote was written by Haun Saussy, 2020.

The author of the following essay, Liu Dong, born in 1955, is currently professor of philosophy at Tsinghua University in Beijing and vice dean of the Tsinghua Guoxue yuan, sometimes translated as "Academy of Chinese Learning." Perhaps an explanation of the Guoxue yuan is the quickest way to situate Liu Dong on the map of current Chinese intellectual positions. The term guoxue (国学, state + learning) first appeared in Chinese as a calque on the equivalent Japanese term, kokugaku or "National Studies" (in Japan of course it referred to Japanese studies). The Guoxue yuan of the Tsinghua School (later Tsinghua University) in the I920s was the home of traditional Chinese scholarship on the Chinese past. Among its best-known professors were Wang Guowei and Liang Qichao, traditionally educated scholars who had guided the abortive modernization reforms of I898, and Zhao Yuanren and Chen Yinque, specialists in the newer disciplines of linguistics and Asian studies who had been educated abroad. Consistent with preI 900 conceptions of knowledge in China, the Guoxue yuan did not conceive of philosophy, history, literature, and statecraft as separate disciplines. The present Guoxue yuan, headed by Chen Lai, seeks likewise 
to recover the premodern community of disciplines, guided by the Confucian model of the "accomplished person" who is "broadened by culture and restrained by ritual" (Analects 9.II). On the face of it, this is an archaistic project, but it offers avenues for comprehensive discussion that narrow disciplinarity often precludes.

History must be at the center of Guoxue's practice, not only because China can claim the world's longest continuous history and biggest historical record (hundreds of millions of words in the dynastic histories and the Classics, with new documents constantly being added through archaeological discoveries) but because drawing the right lessons from history was the core capacity on which the traditional Chinese literatus was tested, and because China is still governed by a party-state apparatus that asserts its own justification through socalled laws of history. What history will consist of and how much latitude will be permitted in the interpretation of specific meaningful historical events are intensely serious issues on which the state brings to bear its censorial, punitive, and remunerative powers. The "patriotic" version of events (some of which may have occurred four thousand years ago) is not easily challenged. Research in other areas is actively discouraged. And yet thousands of young Chinese seek degrees in history abroad every year, where they are exposed to a different sort of competition and a different set of protocols for evaluating historical work. The present essay reflects on all these issues, taking as its starting point the split between two senses of the word "history," in English as in Chinese: the record, and the events to which the record refers (respectively, History B and History A in Liu Dong's analysis). History B is never final; rival versions of History $B$ constantly surface and perturb the understanding of History A, prompting reactions from the defenders of one or another History B. At the same time, professional competition within the marketplace of history writing challenges monopolies on the meaning of history in ways that are sometimes trivial, sometimes consequential. Liu Dong surveys the pluralism of the 
current Chinese experience of "history," both as written and as lived, with a touch of satire backed by his appeal to the standard-setting figures of Wang Guowei and Chen Yinque.

Attempting to reproduce the humor and style of this piece while making it available to a new public has given the translators some pains and joys. It is digressive, anecdotal, not always fair to its targets, abrupt, pointed-and in all these ways of refusing to offer a transparent exposition of facts, it indirectly informs us about the conditions of discourse in China today as pressures to conform to an ever tighter set of requirements make themselves felt even at the summits of the educational system. It contributes, then, to the history of knowledge in two ways: as outward gaze and as self-reflection.

\section{Two Ways of Writing History}

In what sense can we say that "people make their own history"?

If we begin to take this sentence apart, two different meanings will emerge. Of these, the simpler is to take "history" as referring to human history. As agents of this history, humans take initiatives and create historical trajectories through their actions. In this sense, "writing" is merely a convenient metaphor. It refers to the traces that subjects have left in time up to the present, inadvertent by-products of those subjects' vitality.

At the same time, there is another meaning that derives from the above definition, one that is somewhat more complex. It refers to the fact that people, motivated by dissatisfaction or suspicion, often consciously embellish or gloss over the traces they or others have left, making them either sharper or blurrier than before. Only this instance can literally be considered a "writing" of history, for through such acts of writing, the course of the past is recreated. 
Thus, accordingly, we have two different trajectories for history, which we may as well call "History A" and "History B." Of course, a clear-cut dichotomy would unavoidably appear mechanical, monotonous, and fragmented, so it must be added that both dimensions of history have always been indispensable and imply one another. There can be no way of drawing a sharp line between them.

Moreover, as we are limited by our epistemological capacity, the distinction between the two kinds of history, A and B, calls to mind the apparently superfluous but nonetheless indispensable thing-initself that hung above Kant's head. This implies, on the one hand, that we must maintain the presupposition of the existence of History A; otherwise all knowledge loses its source, as well as its capacity to be verified and proved. On the other hand, even if the "thing-in-itself" actually exists for this kind of historiography, we, being concrete mediating links in the course of civilization, are not equipped with the "rational intuition" to comprehend it completely.

In his History in Three Keys, Paul A. Cohen argued, although perhaps too boldly, that history is separately and successively presented before us in three forms-namely, as "event," "experience," and "myth." However, for the sake of inquiry, we may well ask, of all the past events we have read about, which has been truly narrated objectively? Are any completely free of mystification? In this sense, the "event" as Cohen recounts it in his analysis of histories of the Boxer movement takes on the qualities of a "thing-in-itself" for historiography.

Putting aside this kind of simple yet persistent "a priori illusion," the troublesome result is the suspicion that, although History A is man-made in one sense, after a certain time has passed, in most cases we are able to access nothing other than the mediated History B. This mediation is the core concern of this article. When earlier historians selected and compiled materials, they were motivated by the clear objective of actively shaping knowledge. Then we the subsequent historians find those already-compiled histories imposed on us as if by an 
order of fate. Later-born historians must expend a corresponding effort of resistance in order to return our knowledge, at least minimally, to History A.

\section{The Discursive Power of Historians}

In keeping with these observations, we might go on to call History A "history as event," while History B becomes "history as written." But it is worth noting that, no matter whether it is understood as a "fine line" or something more "flexible," the difference between "actual" and "written" history will always exert a unique and subtle pressure on the course of human events.

Precisely because of this, even though the professions of historian or historiographer must be considered to have appeared early on in the social division of labor [in China], their practitioners are repeatedly forced to redo work that was previously declared complete. This notwithstanding, on account of the interaction between the two kinds of history in question, whatever consciously undertaken "writing" by humans has emerged from history itself can never have come about all at once, nor can it have remained in a stable condition. Therefore, even if the course of human affairs is in part "continuous," its "continuity" at the same time derives from the two kinds of history described above and especially from the way the two kinds keep each other in check.

In this the agency of humankind is revealed. We know from psychology that when children acquire the ability to lie, this does not imply a moral defect in them but an advance in their intellect. Similarly, although all living things have their own natural history, only modern-type Homo sapiens populations have the ability to consciously and vigilantly review their own history. Moreover, humans quite consciously overlay and apply the two kinds of mark-making activity: first the actions that result in a history on the level of reality, and then the 
writing that inscribes it onto a virtual level so as even more actively to set a direction for the future. It is precisely through these two levels of creative activity that they achieve the ability to transcend the brief duration of their individual lives and to influence the development of future history.

Unfortunately, those who are trapped within contemporary disciplinary divisions-even if they specialize in writing history-have a hard time realizing as consciously as their predecessors did that those engaged in tracing and embellishing the traces of past events, "molding and influencing the generations to come," and establishing continuity by "linking past and future," are hardly a pack of ivory-tower scholars and useless bookworms. On the contrary, historical agency has always been in their hands; they may even have surreptitiously achieved a monopoly over the awesome power of discourse on human society.

In terms of intergenerational parity, those individuals born in later eras, necessarily having undergone the decisive influence of their predecessors, will in due course possess a similar agency themselves and even out the score. That is to say, although they will inevitably inherit certain preconceptions, they will just as inevitably seek to revise established patterns of history, thereby at least partially resisting the "fate" left to them by their predecessors. Furthermore, their effort at partial correction is bound to occur in the angle between the two kinds of histories: the virtual effort they expend in "writing history" will also certainly combine with real efforts in the sphere of "history as event."

A long and broad view causes us to realize that, despite the fact that we ourselves can neither return to the past nor alter the actual course of History A, historians, similarly endowed with the spirit of agency and therefore laying claim to the power of discourse, can still change and rectify History B, so as to minutely adjust its trajectory from past to present and bend and correct the trajectory's forward path. Precisely for this reason, the subliminal labor of historical "track-shifting" 
is absolutely no tempest in a teacup but in fact may be loaded with dramatic "counter-power."

\section{The Collapse of Written History}

One often hears, in books on business and the like, that the Chinese word for "crisis" also means "opportunity." As so often, this is a halftruth. It makes sense only if one glosses the modern Chinese term weiji 危机 [crisis] as if it were an ambiguous abbreviation for either weixian + jiyu (危险 + 机遇, danger + opportunity) or, more optimistically, weizhong youji (危中有机, there is opportunity in danger). Rather than "timeless Chinese wisdom," we have here a typical semantic ambiguity.

But from the viewpoint of this article, human society's own "opportunity in danger" is specifically manifested in the space between History A and History B. That is to say, if History B is constantly constructing narrative "continuity," then the details it unwittingly or consciously overlooks, which hide in History A, will never fail to manifest as fault lines on the written page, incessantly making a demand for discontinuity. Consequently, the so-called danger + opportunity occurs synchronously in this way: those random events occurring in "history as event" but never accepted into "written history" on the grounds that they were too insignificant or merely fortuitous, will indeed be expressed as earlier historians' "danger" and be manifested as later historians' "opportunity."

To get to the root of the matter, the breed of "modern Homo sapiens" that long ago walked out of East Africa and now covers the whole earth displays both "continuity" and "discontinuity." It is no coincidence that, in the midst of the boundless mass of people, certain grand historical narratives ("grands récits") inevitably form the central point of any set of concentric circles, the core of any kind of compelling identity. ${ }^{3}$ It is precisely those grand ancient narratives that answer the questions posed by the Impressionist painter Gauguin: 
"Where do we come from? What are we? Where are we going?"4 Such narratives also set up virtual fences between "us" and "them."

In the past development of civilizations, any outward extension of these concentric circles indicated an outward broadening of the corresponding narratives. China's early Book of Documents (Shangshu), the Homeric epics of Greece, and the Hebrew Bible use legendary forms to record their respective peoples' origin and progress. Astonishingly, the History B presented in these venerated classics is in fact quite unverifiable as to its content and exceeds the bounds of possible human knowledge. In this way, centuries before Benedict Anderson wrote of "imagined communities," centuries before the development of the printing press, people had already formed "imagined communities" by reciting orally transmitted texts. ${ }^{5}$

But it is only in the present white-hot, thronging era of globalization that we have suddenly discovered, to our alarm, that grand narratives have burst like a bubble. Speaking more concretely, from the moment that the many self-sufficient grand narratives of different civilizations take the same stage, they neutralize one another. What Max Weber called "a war of gods" refers to precisely this kind of mutual subversion and wholesale rejection. ${ }^{6}$ In this sense, the "plural" in so-called pluralism, already highly exaggerated and overused, may come down to nothing more than a kind of disconcerting coexistence, one that has no "-ism" to hold onto, because no matter how tolerant people aspire to be-or possibly precisely because they are already too tolerant-they cannot subscribe to several complete and exclusive narratives at the same time.

The consequences are not hard to see: even though those stories still exist in their original form, people long ago lost the frame of mind needed to take them seriously; they can at most regard them as harmless legends. The only thing left to take their place was the evolution of living beings in the Darwinian sense; for present-day people, this theory is no doubt the only historical narrative that still sounds believable. 
Sadly, to borrow Wang Guowei's remark in "Truth and Freedom," philosophical ideas that are aesthetically "pleasing" are not usually "credible," and those that are "credible" are not usually "pleasing." Indeed, there is not much to like in this seemingly "credible" story. And as I have put it elsewhere, once the biological sciences move directly onto the territory of the humanities, they will certainly drag it from civilization back to a primitive jungle. ${ }^{8}$

In the words of Anthony Ludovici, an early English-language follower of Nietzsche,

[Should] the triumph of science mean "the Descent of Man"; if the glories of enlightenment mean, again, the descent of man; and if progress imply, once more, the descent of man; then the question to be asked is: in whose hands have science, enlightenment and the care of progress fallen?

This world is here for us to make of it what we will. It is a field of yielding clay, in which like sandboys, we can build our castles and revel in our creations. But what are these people doing? In building their castles they grow ever more like beavers, ants, and beetles. In laying out their gardens they grow ever more like slugs, and worms, and centipedes. And their joy seems to be to feel themselves small and despised. ${ }^{9}$

Early modern history witnessed incessant and destructive conflicts between native-born and immigrant populations in continental Europe and the Anglo-American world, nations that prided themselves on being "civilized." Samuel Huntington has described these conflicts as "clashes of civilizations." ${ }^{\circ}$ But in keeping with the train of thought of the present article, we might have spoken of conflicts "among narratives" or "among legends"-forms of conflict that are hopeless and unending. 


\section{The Composite Function of History B}

What, in the end, does all this mean? The chief concern of this article is to suggest that under severe pressure from the global context, the card shuffling of contemporary science is quick to affect History A: History A then constantly changes shape, expands, and recombines and thereby finds itself in a life-or-death struggle with each civilization's History B.

Indeed, from the perspective of historiography, contemporary humanity faces a dilemma. On the one hand, people still need stories just as in the old times-stories that can be handed down across generations, to consolidate their faith in their course of history and reinforce the cohesion of the community to which they belong. On the other hand, once that kind of story has been soaked in the solvent of science and reduced to its original, unadulterated, barest elements, then nothing is left of it but a mockery of bygone life, and its former cultural functions fade away. If only our contemporaries were at least able to recognize the fact, those "holdovers" mercilessly pared away by science are exactly where the essence of these grand narratives is to be found.

People still cannot for a moment do without that kind of story. This aspect of human psychology has not experienced the slightest evolution. And precisely because of this need, the stories that passed for the equivalent of "written history" in former times, consonant with emotional if not rational truth, exhibited a nationalistic discourse that was even more narrow, conformist, and exclusionary in character. An adulterated history of this kind satisfies people's need for a common origin, as long as they are subjectively willing to believe it or are forced to do so. But in the end, it will only delineate a fixed boundary with the outside, which for them serves as a simple distinction between good and evil, crudely defined. But it leaves all other functions of culture as a blank. Such a regression cannot actually be described as typical of 
the "primitive jungle"-because forest tribes can be said to have "developed" their technology, but people in the grip of an identitarian myth are just barbarians condemned to live on a powder keg.

Let us take the East Asia region we live in as an example. No matter how often we say that there is only one History A, or that there can reasonably be only one "real history of events," historical discourses differ in terms of selection and arrangement of historical materials. Thus, Chinese and Japanese, Japanese and Koreans, South and North Koreans, those living in Mainland China, and those in Taiwan all have their own, often mutually contradictory versions of History B. Indeed, even among Mainlanders themselves, rapid societal shifts and repeated upheavals have led those specifically searching for the cracks in history and those merely content with official versions of history to follow diverging paths. Depending on what parts of the historical record they are willing to believe or disbelieve, their "writing of history" takes opposite forms and on that basis builds up competing cliques.

From this angle it appears that the popularity of global historiography in recent years reveals a desire to achieve a broadly globalized vision and to integrate previously fractured, constricted, and fragmented grand narratives. In this sense, this lecture of mine, delivered at the University of Chicago, is a tribute to the late William McNeill. ${ }^{\text {II }}$ Even so, I would call the desire for integration insufficient from the standpoint of philosophy and note that even the area of history McNeill specialized in has already been swept across and left in disarray by contemporary science. ${ }^{\mathrm{I} 2}$ The most we can do now [in constructing a history of the human race] is to rely on the driest, barest historiography as now understood and follow Darwin's account of the story of humankind; there is no way to stand apart from it and repair the cracks in civilization.

Allow me to draw another analogy. Although the specifics differ, this situation bears some similarity to the contemporary handling of religion. On the one hand, the Enlightenment had to firmly reject 
religious thought-a standard of absolute rationalism that holds to the present, that didn't allow people simply to turn back the wheels of history [as if religion had never existed]. But on the other hand, even allowing for the shortcomings of religious thought, since it is extremely arbitrary and exclusive and its arbitrariness and exclusiveness make it increasingly a source of contemporary conflicts and division, we must admit that much that was once associated with religion, including ethics and art, a sense of community and identification, belongs among the glorious creations of human civilization and is indeed a necessary foundation of human society. We cannot throw these pleasing babies out with the bathwater.

Somewhat along these lines, I published a paper in 2016 that already dealt prominently with the "didactic history" specific to ancient China. It demonstrated that historiography, at least traditionally in China, is an invention both comprehensive in content and conciliatory in function: "Thus, not even the sharp eyes of comparative literature would be entitled to equate the culture of the Historical Writings (shibu 史部) in traditional China with Western 'History.' Or to say it less sharply: on the genealogical table of human knowledge, the Historical Writings are more tilted toward the side of the humanities, while 'History' inclines to that of the sciences. Or may we not simply argue: 'history' in traditional Chinese culture is not a system of knowledge, but belongs to a value system?"'3

However, here we must again blur fixed "binaries." In reality, whatever relative differences and divergencies exist between China and the West, we still belong to one and the same human race, and [every subgroup] still demands an origin point for its centripetal motion. Thus, any [global] historical narrative we construct is bound to be a multilayered compromise. If it is to explain the origin and development of humanity, our narrative is also bound to include elements of ethics and art, as well as supporting community and identification. In this sense, history's current crisis manifests itself very pointedly 
in what follows: because of the ceaseless development of new scientific discoveries and methods, the History A that used to be masked by "written history" inevitably pierces through past historiographies and reappears in the form of new finds or left-out materials that constantly disprove and deconstruct the History B that used to support the humanistic world.

Naturally, on top of this, a more serious crisis is manifested in the fact that, under the impact of modern science, even historiography itself has been laid bare and is only seen as a special form of empirical science. Actually, borrowing again from Cohen, we can say that such historical narratives from the outset have always been pitched in the keys of both "event" and "myth." Let us remember what Giambattista Vico once said: "So, at first, man proceeds by these various means, follows traces of the nature of things and eventually upon reflection realizes that he cannot arrive at the nature of things on this basis because he does not have within himself the elements in accordance with which composite things exist; in addition, he realizes that this is the result of the limited scope of his mind, for all things are outside that mind." ${ }^{4}$ Then, having peeled away the components of "myth" and "human culture," we should at the very least have developed an adequate sense of crisis to ask whether and how this "disenchanted" scientific history can preserve in any measure the identity fashioning of humanity.

\section{The Subversiveness of Historical Materials Themselves}

Let us now take another direction. On the basis of what the preceding section laid out concerning the tension between History A and History B, this section's heading announces that historical materials themselves can, in fact, be subversive in nature.

Generally, people are apt to suppose that, since compiling history is an action, historical materials passively await their compilation by 
contemporary or successive editors, like objects waiting to be sorted out. But as Hu Shi remarked in his introduction to William James's thought: "Reality is the reality that we ourselves have altered. Within this reality are many artificial elements. Reality is a docile maid. She does not resist our attempts to adjust her make-up and dressing." ${ }^{\text {"5 }}$ Hu's statement can stand for a classic misunderstanding about the nature of historical materials.

In reality, historical materials are not nearly so malleable or docile; on the contrary, they contain an inherent subversiveness. In terms of their basic nature, historical materials' potential for subversion comes from the dual definition of history itself. That is to say, any skillfully composed description of past events will comprise, in its basic form of expression, memory as much as imagination, fact as much as myth, science as much as humanistic study. For this reason, history writing belongs among both the knowledge-generating professions and among the manifestations of power.

Precisely for this reason, given the decisive influence of the first group of factors, historians of every generation must compose historical narratives that are both persuasive and supported by the historical materials or documents. Even the most insightful, sensitive, motivated, and conscientious scholar must scrutinize, select, and organize materials. This is the string that reins in the kite of his or her imagination. It is for this reason, again, given the decisive influence of the first group of factors, that historians' work will be judged by the impossibility of proving a negative. Because their work involves drawing conclusions from facts, what they most fear is the unacknowledged presence of a black swan-that is, some document that they failed to consult-which can make their years of toil collapse overnight.

However, we come to the uncomfortable realization that, no matter how hard the earlier historians tried, it was precisely because they had to rely on their subjective creativity that they had tremendous difficulty in bringing the history they wrote into complete unity and harmony 
with the historical materials it was based on. For this reason, when subsequent historians bring their agency into play, not without their own individual ambitions, while stepping to the beat of their own era, they are bound to seek out tension and cracks among the materials. Therefore, using historical materials that have been wittingly or unwittingly neglected means reopening the History B or "written history" produced in the past. And it is exactly in this sense that we cannot stop dynamic historical materials from working like quicksand beneath the surface; their constant movement makes the foundations we have poured inherently unstable, so that the authority of past historiography is never unassailable.

For this reason-if I may draw another analogy—these subversive historical materials actually resemble the constantly shifting productive forces in Karl Marx's theory, as opposed to the relatively stable superstructure. First of all, the uninterrupted manifestation of various kinds of truth-seeking activities-from archaeological excavation to the sequencing of the human genome-results in a continuous stream of historical materials, some of which are bound to break through the accepted self-understandings of the past. Second, as new disciplines are constantly emerging, such as ethnography or field-based sociology, these cause constant renewal in the techniques of history writing and new frameworks within which to discover previously unnoticed historical materials.

Moreover, the backdrop of increasing globalization alluded to above has brought a massive influx of historiographic materials from outside the boundaries formerly circumscribing civilizations. This influx includes materials in more foreign languages than any individual can learn in a lifetime, as well as historical records that defy anyone's ability to read them. These materials take on an increasing and previously unimagined importance: they forcefully point to a world of things unknown, which only submerges historians even more deeply. In this sense, Sima Qian's stated ambition to "investigate the boundary 
between heaven and man, and to trace the transformations of ancient and present times" (究天人之际, 通古今之变) has become an almost unimaginable task for scholars of today. Therefore, when people today claim to "found a school of thought" (成一家之言) by hastily publishing a few books, it is a useless exercise in boastfulness. ${ }^{16}$

\section{Memory's Turn against Power}

Another aspect of the subversiveness of historical materials: as a result of the burgeoning interest in active participation, the declining legitimacy of authoritarian regimes, the increase of literacy among the population, the media's capacity to quickly transmit information, and even the substantial increase in average lifespan, we nowadays not only deliberately preserve our historical materials but also turn them into a plethora of written histories. These efforts have established a very peculiar form of "counter-power" in our current society.

Accordingly, we may distinguish, in history writing, the writing up of historical research and the writing up of historical materials. The former is known as professional "historiography," while the second can be dubbed "history." But let it be noted that from an excess of confidence in the commensurability of terms between languages, translators in the past simply rendered the Chinese term shibu [the Division of Histories in traditional bibliography, dominated by the officially composed dynastic histories] with the generalized concept of "history" and did not bother to make any more specific distinctions. As a consequence, anyone in society, no matter their professional specialization, or whether they had any historiographical training or technique, could suddenly put pen to paper and author his or her own history, and in most cases the results of this writing would be historical materials and documents.

In all fairness, their doing so would not be without its reasons. Nazi 
written by the victors. ${ }^{17}$ This phrase has equivalents in Chinese: "Succeed and you'll end as a duke, fail and you'll end as a bandit” (成者王侯, 败者戌), or "steal a belt-buckle and be hanged, steal a country and become a marquis" (窃钩者诛, 窃国者侯). ${ }^{18}$ These views, of course, can be led back to the equivalence Michel Foucault noted between discourse and power. However, those left powerless and dispossessed by History A withstand this tendency; in spite of their having neither the authority nor the training to compose a formal History B, they invisibly but increasingly are inclined to devote their remaining years to compiling historical documents. In this way they uncover all kinds of holes, cracks, and counterexamples in official history, as well as leaving challenges and struggles for the historians to come.

Doubtless, by taking such an initiative, they are consciously choosing to write history in the mode of History A, or, to put it another way, they compose a history in the image of the "trend of history" they themselves hope for. That is, on the brink of despair, they maintain hope in the belief that, sooner or later, the indomitable History A they have left behind will ultimately subvert the current, adulterated, History B. Thus, by imparting a counterforce onto subsequent developments, they may alter the trajectory of their descendants' lives. Hence the oppressed in actual history place their hope in historical materials, counting on the day when these materials will emerge in the dialectic of history to help them change places with the oppressors and undo the harmful influences the latter have imposed on history.

In an as yet unpublished article I have described one such phenomenon: "writing by the elderly" in China today:

On the one hand, if we look at it objectively, the life of the person who has entered this stage of writing must truly be full of sorrow. That is to say, one cannot expect to deal with a lifetime's leftover issues-correcting mistakes, redressing wrongs-in the years that remain; one can only leave them to subsequent history, by entrusting 
to its care this sliver of vague but deep-seated hope. But on the other hand, we can say that those who write their own history are still exercising certain freedoms. Through their trust in the agency of authorship, whether the purpose be an appeal to public opinion by the oppressed or an attempt at self-justification by the defeated, a starting-point of equality is created from the moment they unroll the blank page and stretch their thoughts to historical dimensions. Not even the holders of power and the flatterers who chant "Ten thousand years!" can rule there, though in the world where they dominate the "language of the victors" is still spoken. ${ }^{\text {I9 }}$

In that essay I also pointed out that the rapid expansion of consumerism [in China] has left in its wake only an omnipresent materialism, particularly among young people, who constitute the main body of consumers. Fixated on all the material opportunities and pleasures available in the bustling and well-stocked marketplace, they have little time to look back at history, let alone ahead to the future. But this is precisely what has allowed China's elderly population a rare chance to be creative:

Future generations, when examining the products of the spirit of our age, will find it surprising and even baffling that it was old people who, guided by a moral imperative, spared no effort in recording [events] faithfully and breaking the silence. They have done so in place of those who were originally supposed to shoulder the responsibilities, to ensure that today's history would not be left as an utter blank. In this sense, their writing in the last phases of life more than any other approximates the very essence of writing, imbued with an existential sense of urgency and a sense of history and justice. ${ }^{20}$

To be sure, although one need not have reached one's twilight years

to accomplish this, the trend of digging up and calling attention to 
historical materials is not unique to contemporary China but is a common trend directed at the power that operates behind discourse. For instance, as my colleague Peng Gang has related, following the postmodern disintegration of grand historical narratives, history all over the world appears to have undergone a "memorial turn":

Seen from the critical perspective of postmodernism, the history that emerged alongside the collective rise of nation-states and served to justify them has evolved into an instrument of oppression (of women, colonized peoples, marginalized groups, etc.). Unitary History "with a big H" trumped diverse histories. In that History it is men, nations, the West, rationality, and objectivity that occupy the determining position. Correspondingly, the factors related to women, localism, colonized peoples, irrationality, marginalized groups, subjectivity, etc., have been suppressed, banished, or relegated to the fringes of History. Because memory has a quasi-natural affinity with the latter group, historical memories have increasingly drawn attention from researchers in historiography and theorists of history, for whom History is replaced by a plurality of histories. ${ }^{2 \mathrm{I}}$

In quite similar terms the French scholar Pierre Nora has pointed out how buried, nearly invisible memories have returned to the very center of contemporary historical studies, as the oppressed virtually rise from their graves against their oppressors and achieve representation through these dynamic historical materials:

Recent years have seen a revival of the historical novel, a vogue for personal memoirs, a revitalization of historical drama, and the rise of oral history. What can account for all these things if not that they are somehow stand-ins for faltering fiction? Our interest in the lieux de mémoire in which our depleted fund of collective memory is rooted, concentrated, and expressed stems from this new sensibility. History 
offers profundity to an epoch devoid of it, true stories to an epoch devoid of real novels. Memory has been promoted to the center of history: thus do we mourn the loss of literature. ${ }^{22}$

This being said, we must still bear in mind that the dividing line between History A and History B is not nearly so clear-cut. Therefore, the degree to which these "memories" and "recollections" can be considered "history as event" and the degree to which they also belong to "written history" demands careful consideration.

\section{History's Degeneration into the Study of Historical Materials}

Let me then return to the point that as a consequence of the large-scale appearance of historical materials and the widespread resurrection of "memory," a potential crisis for history today manifests itself in the fact that all the while that we consciously and self-critically examine history writing, we are not adequately vigilant in recognizing the "double-edged nature" of the historical materials we process.

Piquantly, as both worthy and worthless persons can now pick up the pen-as a result of a more "democratic" production of historical documents-the large-scale preservation and transmission of these documents will lead to cacophony and deadlock. For this reason, one and the same power struggle may produce entirely different memories. Documents written by Kang Youwei and Liang Qichao, who challenged the Empress Dowager, or by Solzhenitsyn and Shostakovich, who defied Stalin, would definitely affect us in a different way than do Chen Boda's "recollections." ${ }^{23}$ Furthermore, according to the disciplinary restrictions in place today, retired party cadres are not generally allowed to write their own memoirs. The absence of such restrictions made it possible for the memoirs of Huang Yongsheng, $\mathrm{Wu}$ 
to sell well on the Hong Kong book market. ${ }^{24}$ Their whitewashing of Lin Biao may have contributed to a positive feeling toward "Vice Premier Lin" among some young people whose knowledge of the Cultural Revolution remains partial. ${ }^{25}$ Such ignorance and misunderstanding are quite worrisome.

For this very reason, any well-trained historian must treat memoirs of this kind with extreme caution, even if they actually imply the existence of cracks and holes in History B, for the subversion they bring can sometimes only add to confusion and dismay. For even if each discovery of new historical materials fills us with excitement and curiosity, once these discoveries have been superposed, they often turn out to contradict one another. The reason is that our current pared-down version of history identifies itself totally with science and has either forgotten or denied its association with the humanities. It was because of such a scientistic attitude that $\mathrm{Hu}$ Shi valued history only as a source of verifiable facts, to the extent of once stating indiscriminately: "To find the ancient meaning of a character is no less a contribution [to knowledge] than discovering a star!" ${ }^{26}$ In this sense, we can even say that the very subversiveness of historical materials actually subverts history itself, to the extent that history is reduced to the collecting of historical materials.

For example, anyone can see that the historical movement in modern China that formed around the journal Gushibian (Debates on ancient history, I926-4I) - the aptly named group of "Doubters of Antiquity," represented by Gu Jiegang-was naturally a self-conscious school of thought driven by the vast wave of modernity. ${ }^{27}$ However, it is not quite so obvious that the "Believers in Antiquity," as represented by Wang Guowei, were also similarly influenced by imported ideas of history and even more emphatically stressed the decisive role of historical materials. ${ }^{28}$ Thus, Wang's school, no less than the Doubters, attests to the modern transformation in Chinese historical studies. Let us now reexamine a lecture Wang gave at the Tsinghua Academy: 
The emergence of new forms of scholarship has typically been the result of new discoveries... The three greatest discoveries of Chinese scholarship since the Han dynasty have been: first, the ancient texts discovered in the wall of Confucius' ancestral home; second, the ancient bamboo slips discovered at Jizhong; and third, in our times, the Shang oracle bones unearthed at the Yinxu site [Anyang, Henan Province], the Han- and Jin-dynasty wood slips found near the Dunhuang Pass and all around the Western territories [xiyu, the region west of the Jade Pass in central Asia], the Six Dynasties and Tang dynasty scrolls found in the caves at Dunhuang, and the Yuan-Ming dynasty ministerial archives from the Forbidden City. In terms of their significance, these four modernday discoveries are on par with what had been found in Confucius' ancestral home and in Jizhong. And I have not yet mentioned the various inscriptions on bronze and stone and other writings recovered here and there that have been of extreme importance to scholarship. Thus, we can say that we presently live in an era of unparalleled discovery. ${ }^{29}$

Most people would assume that since Wang Guowei's topic was the "Believers in Antiquity," his attention to these new materials was intended to substantiate their view. But looking at it now, I find a certain amount of hidden subversion in Wang's remarks. For the emergence of historical materials always carries some element of chance. If the good Lord had determined to allocate the discovery of new things in an equitable and uniform manner, that would be one thing; but it is not so, and once people have begun to assume that the antiquity we know reflects a representative sampling of all the possible evidence, wherever historical materials have cropped up, they are apt to focus with tunnel vision on this area of available knowledge, and the resulting specialization will warp their perspective on history. However, as far as the configuration of the whole field of history goes, the hot spots 
are always hot relative to the cold and ignored areas, and interest is relative to indifference. The rush to areas buzzing with activity, neglecting the wider cultural background, is bound to create a corresponding bias and imbalance of attention.

Under these circumstances, we can appreciate anew these words of Jacob Burckhardt: "In scholarship . . . a man can only be a master in one particular field, namely as a specialist, and in some field he should be a specialist. But if he is not to forfeit his capacity for taking a general view, or even his respect for general views, he should be an amateur at as many points as possible, privately at any rate, for the increase of his own knowledge and the enrichment of his possible standpoints. Otherwise he will remain ignorant in any field lying outside his own specialty, and perhaps, as a man, a barbarian." ${ }^{\circ 0}$

Indeed, were it not for our equating history with modern science and assigning merit and prizes to historians for their "creativity," the vogue for new historical materials appears as a short-term phenomenon. It is a type of history that contributes to general culture and in a certain degree expands the frontiers of knowledge, but in the larger perspective of development it is unlikely to supply broad views and deep insights. Needless to say, compared to [Sima Qian's] aspiration to "investigate the boundary between heaven and man, and trace the transformations of ancient and present times," this [innovationoriented] history, devoid of the flavor of antiquity and reflective of a professional mindset, is certain to thwart the intellectual development of those who engage in historical research. For this reason, it becomes more and more sensible that genuinely self-respecting historians in the grand style should not be excessively concerned with fortuitous historical materials. At the very least, they do not stake their academic careers on them.

Wang Guowei is certainly an exception to this rule. He possessed an unusual combination of talent, erudition, and refined taste. The great insights that Wang cultivated through his early immersion in Western 
learning, his insatiable thirst for knowledge about other fields, and his readiness to make the most of the unique opportunities that were available to him-very few of his epigones can match him in any of these respects. Therefore, while affirming Wang's great achievements, we must also recognize his negative influence. His example has convinced many scholars that by acquiring one special skill they can become universal polymaths, even when they know little about other subjects, have inadequate historical training, or are lacking in moral character. In order to sharpen the contrast, I would like to quote an antagonistic comment that Qian Mu once made:

While from ancient times, various kinds of so-called specialized areas of learning have existed in China, such as astrology, calendarmaking, arithmetic, medicine, etc., today, all these belong to the natural sciences. These are fields where the man is hidden behind the learning rather than the learning bringing out the man. Accordingly, the ancient Chinese traditions almost entirely neglect such areas of knowledge. To tell the truth, it was not neglect, but a concentrated effort to keep people from specializing in compartmented and discontinuous learning. A contrast is seen in the six Confucian arts-rites, music, archery, charioteering, literacy, and arithmetic. Were any of these arts to be practiced independently from the development of human character, then in practicing them, the student would treat learning as the principal thing and human character as a secondary thing, against which Confucius sharply warned.... Thus when Confucius taught men to study the Six Arts, he insisted that "their will be set on the Way, their attainment be firmly grasped in virtue, their action in accordance with benevolence, and their relaxation and enjoyment be found in the polite arts" [Analects 7.6]. The Arts and the Way are not the same. Should one substitute "enjoyment in the polite arts" for learning, and remain ignorant of everything else, this should rather be called 
an indulgence in the arts that results in turning one's back on the Way. ${ }^{3 \mathrm{I}}$

It is sad to see history becoming a "career" for people who wish to "be creative," unlike the "universally learned person" of the past. These historians believe it their profession to "rewrite" history, regardless of whether they have themselves identified a need or a way to rewrite it. For them, the key to being able to complete this duty of rewriting lies in getting one's hands on new historical materials, on which their academic reputation, career prospects, promotion, and even their livelihoods depend. The rest, including self-cultivation through the study of history, is not at all their concern. And the stories they retell, although exhibiting some remote connection to the actual character of history, are dominated and hemmed in by those historical materials.

A remark of Zhang Zai's seems to have been uttered with reference to today's maladies: "Those who come to study but set their mind on achievement first are in conflict with their own learning. Their ambition causes them to split hairs, invent meanings, and extrapolate consequences. To pursue achievement without having achieved moral character is like using a broadax [without training]: rare are those who would not get their hands hurt." ${ }^{22}$ Those who are so eager for "academic innovation" would do well to heed another of Zhang Zai's comments: "Those who have not perfected their learning but talk about change will eventually bring trouble. For changes cannot be discussed lightly. If someone talks about change in an abrupt manner, you can be certain that his principles are crooked." 33

In the past, when reading students' dissertations, whenever I saw comprehensive reviews of secondary literature, I would think, considering how much time these take to compile, that at least I should give credit for hard work even in the absence of merit. But today, the minute I see such reviews, I know the game that's being played, because the new-generation scholars know how to plow through databases, 
transforming what used to be free and wide-ranging reading into targeted word searches on a narrow topic. What is simultaneously laughable and deplorable is that, although many of the doctoral students I advise cannot come up with worthwhile research questions on their own, as soon as I help them come up with a question, they run to do a computer search and can instantly deliver a dizzying mass of related citations. This hardly appears to be a Chinese "local disease." My colleague in the United States Alexander Des Forges provides the following interesting description: "A searchable database is analogous to the cyclotron accelerators that physicists use. One types in search words and phrases, and then closely inspects the output to see what information has been retrieved. The text thus becomes the target of repeated searches. Then what are the significant differences between physicists using cyclotron accelerators or chemists using pulverizers and humanists relying on traditional reading methods? What is the difference between reading and searching? The main difference likely lies in the historical nature of the reading process." 34

\section{What Is Left for Historians?}

Recently, the defeat of the Go player Lee Se-dol by the computer program "Alphago" stripped Homo sapiens almost entirely of our last vestige of pride. ${ }^{35}$ One could not help wondering: Will not the "accelerator" method described above, with its pulverizing and blending, soon turn history into an enterprise ghostwritten and completed by machines, from the initial selection of topics to the final write-up? To be sure, the "acceleration" effect of such a writing method must appear desirable in statistical terms, so that it would definitely find favor with technocratic administrators and fit with the new generation's academic culture.

Yet machines have the intrinsic deficiency of lacking all practical 
humans, even if they are exempt from the human problems of bias and limitation. This deficiency should impel us all the more to reflect on the issue from the opposite side: the crucial element in the process of researching and writing history lies in our own agency, in what we have comprehended through the activities of our own lives, and in the vivid experience that brings us the benefit of wisdom. For this reason, no matter how easy it may be to obtain historical materials, materials are no substitute for the thinking of historians themselves; and precisely because it has become so easy to collect historical materials, a researcher who rambles and overenumerates historical details will not display the technical mastery of a Qian Zhongshu. ${ }^{36}$ Thus, the writing of history in our age demands ever more thought and technique.

There is something ironic in the fact that ever since the traditional Chinese [bibliographical] categorization of "classics, histories, masters, collections" was combined with the Western [disciplinary] division of "literature, history, philosophy," scholars engaged in historical research keep treating history as history and philosophy as philosophy, as if to say never the twain shall meet. Those purportedly engaged in "intellectual history" even mistakenly assume that one need only catalog the historical materials pertaining to thought, as if all one needs to do is leave thinking to the thinkers of the past and, for one's own part, simply enumerate their thoughts, so as to compile what must count as a hefty work of intellectual history. The key thing they fail to realize is that, in a decisive sense, historiography itself should belong to the history of thought; any historical compilation that lacks an intellectual dynamic and ethical purview can only count as confusion: "Fragmented, banal reports to the throne." 37

And for this reason, we must declare forthrightly that, on the one hand, the process of writing history must remain a "truth-seeking endeavor"; otherwise, it would be hard to avoid descending into Hu Shi's instrumentalism, the assumption that historical materials can indeed be rearranged at will. But on the other hand, one cannot reduce the 
work of history merely to this same "truth-seeking" endeavor, or see it simply as implementing "historical empiricism"; in either case, one will only be engulfed in the boundless maze of historical materials. To put it more bluntly: on the one hand, in order to be receptive and draw from past human experience, we must of course form our thinking by means of archival materials; but on the other, we must be fully alert to the fact that archives will not think for us. Rather, the more thickly they pile up, the more they may drown out our own thoughts.

And so, we must acknowledge that, being him- or herself a limited "Dasein," the historian is fated to encounter the "tragedy of knowing" as does Faust in the first scene of Goethe's play; or, perhaps to find themselves in the situation that Zhuangzi described: "Your life has a limit but knowledge has none. If you use what is limited to pursue what has no limit, you will be in danger." ${ }^{38}$ In this regard, those intending to write history, no matter how much energy they are prepared to dedicate to the search for materials, must know that in the end the supply of historical materials is inexhaustible. Indeed, supposing one could drain the pond to get all the fish, that would surely overwhelm one's quest for the truth and dissolve the impulse to explain. For this reason, we must tranquilly accept the paradox that, although, on the one hand, the course of human life is historical and gradual-the very reason for which humanity has created the field of "history" to explore it-on the other hand, precisely because our individual lives are equally historical in nature, we do not have the requisite time to grasp in any full or comprehensive way the courses of our lives as they unfold.

After all this "blunt talk," I still have a well-nigh "interminable" task before me-namely, answering the question: What are historians ultimately left with? Has their mission, passed down from generation to generation, become despondent and moribund? Not necessarily, because, as I see it, historians may yet come back to life; as long as they can achieve a high degree of balance, on the one hand, by accepting that although historians, as individuals, must always be ready to confront 
the challenges of history, they must also be resigned to our life's limitations, and on the other, by never forgetting that, working collectively, historians create history, as long as their tradition is uninterrupted.

We can refer to a relevant text. In his preface to A New Discussion of National History, Qian Mu very clearly pointed out the aim of his political history: "In a time of turbulence and inexorable, limitless change, a nation's historical past acts as an invisible hand to lead it forward with infinite power and keep it from going astray." Precisely because he understood this opportunity and responsibility, Qian Mu could "go beyond [his] capacities in seeking to supply the needs of a new era by looking back to the past, to re-evaluate the veracity of our old histories, in order to trace the sources and examine the real causes of our country's present problems." ${ }^{39}$ However, even against this background of "danger and opportunity coexisting," the author did not forget that "excess and deficiency are both vices." On the one hand, one must do one's utmost to get at the truth: "I will use historical facts as the basis for an impartial and objective inquiry. I will not distort facts to cater to the needs of a particular movement or ruling party and justify the status quo. For only thus can scholarship gain its independence, and knowledge claim its real value and effects." But on the other hand, looking at himself realistically, and waiting magnanimously for those to follow, he says: "Although every statement I make can be traced to a source and every event I describe is based on facts, it is no easy task to include everything one can glean from the infinitely large corpus of historical texts. I hope the reader can forgive my errors and address what I have overlooked." ${ }^{40}$ Here is indeed the principle every great historian should adhere to. This is what it means to have a feeling for history!

In closing, let me turn to Confucius. Although no "professional," Confucius is arguably the historian among all Chinese historians. He turned to writing and compiling history after withdrawing from an unsuccessful political career. By so doing he expressed his own moral concerns and exhibited a personality whose influence has been without 
equal in the whole course of Chinese history. In my first lecture I cited the famous passage: "When Confucius wrote the Spring and Autumn Annals, undutiful subjects and rebellious sons were terrified." ${ }^{41}$ Confucius, as I said there, "established a paradigm that obliges the Chinese people, in the absence of religious sanctions, to be concerned with how they will be remembered in history. On this depends, to a great extent, whatever is truly humane and upright in Chinese ethics and morality." ${ }^{42}$

Pursuing the road opened by Confucius's writing of history, the basic, unalterable aim of his successors' recording, reminding, and critiquing past events has been to reform and restore the course of history, to lead it back to the conditions under which the Book of Songs, that collection said to be "with no perverse thoughts," was composed: the "Three Eras" marked by "the traces of the Former Kings." ${ }^{43}$ It was not until the Song dynasty that this type of Chinese historiography reached another high point. Further down the line, the historian Chen Yinque was no follower of the mid-Qing school of textual and evidential criticism, as his student Wang Yongxing correctly notes in his A Brief Outline of Chen Yinque's Historiography: he continued the Song-era tradition of [moral and policy-oriented] historiography. ${ }^{44}$ Most people are oblivious to this fact. If we focus only on Chen Yinque's command of many languages and his grasp of an array of historical materials, then we are completely missing the forest for the trees. Moreover, if we who are in the field cannot appreciate his concern for matters of value but merely take his completed work and break it up into scattered points of evidential argument, then there really will be nothing left of the great historian Chen Yinque.

Now to conclude. On the one hand, a subtle tension between History $\mathrm{A}$ and History $\mathrm{B}$, deriving from the effort to understand any historical period or subject, becomes one of the factors regulating historical trends. This should, at least, give us some feeling of gratification. The lamentable thing is that, as this great undertaking is spread over many 
separate lifetimes, any one person's effort can only count as a "part of the whole," which logically means that, while everyone wants to influence history in their lifetime, when all is said and done, none of us has the ability to decide that. Even considering that individuals have "joined forces," it is impossible, owing to the incredibly scattered and irregular nature of the "matrix," to order things into Engels's "parallelogram," because that kind of ideal shape actually implies an assumption of "concurrence of forces"; but this "concurrence" either fits only with an arbitrary historical determinism, or conceals assumptions of an ineffable Providence. ${ }^{45}$

But on the other hand, since we have dispensed with the idea of Providence, any individual's writing of history—be it History A or History B-is best described as a resistance to their particular lot in life; at the very least we can say that their lives manifest an indomitable attitude. Such acts or postures of resistance, although they amount to subtle revisions of established history, are all part of what a normal subject of history naturally desires, because every historical subject that has ever actually existed was, in point of fact, a moral subject. They express their deep-set moral judgments on past historical events, and as for the future, they cannot help laying out moral corrections. Precisely in this sense I have often noted that, regardless of the erroneous, falsified, or even criminal character of the history of the past, the ethical principles within us do not err; they continually spur us to correct the draft of history.

It is even more meaningful that, in this sense, the writing of history, saturated with hope and imagination, transforms into a kind of "aesthetics of history" or "poetics of history." The precious demands that stem from the humanities are, at least, one thing left to historians. They show us a way right in front of us, and that must be to carry forward the humanistic qualities of history, to promote its ethical concerns and poetic imagination, and thereby to draw painful lessons from the history of the past and lend hope to the history of the future. 
Of course, there is another way besides this, which is to keep letting science replace humanism so that History A smothers History B, leaving machines to do our work for us and scattered fragments of historical materials to banish the intensity of imagination. History would then be even further reducing history to a thing of the past, a craft without consequence. But it is already clear that we must go no further down this blind alley. 


\section{Notes}

Translated by Wang Shengyu and Haun Saussy.

I. [Karl Marx, The Eighteenth Brumaire of Louis Bonaparte (New York: International Publishers, 1963), I. Words and notes in square brackets have been added by the translators.]

2. Paul A. Cohen, History in Three Keys: The Boxers as Event, Experience, and Myth (New York: Columbia University Press, 1998).

3. [In the terms of Jean-François Lyotard's analysis, see The Postmodern Condition: A Report on Knowledge, trans. Geoffrey Bennington and Brian Massumi (Minneapolis: University of Minnesota Press, 1984).]

4. [Liu Dong cites the title of Gauguin's painting D'où venons-nous? Que sommes-nous? Où allons-nous? (I898), now in the Museum of Fine Arts, Boston.]

5. [Benedict Anderson, Imagined Communities: Reflections on the Origins and Spread of Nationalism (London: Verso, I983). For a comparative study of the expansion of culturally privileged narratives to cover new territories, see Alexander Beecroft, Authorship and Cultural Identity in Early Greece and China: Patterns of Literary Circulation (Cambridge: Cambridge University Press, 20I0).]

6. [See Max Weber, Wissenschaft als Beruf 1917/1919, Politik als Beruf 1919 (Tübingen: Mohr Siebeck, I992), I00-IOI.]

7. Wang Guowei, “Zi xu er” 自序二, Jing'an wenji xubian 静安文集续编 [Collected essays of Wang Guowei, continued], in Haining Wang Jing'an xiansheng yishu 海宁王 静安先生遗书 [Posthumous edition of Wang Guowei's works] (Haining: Wang shi, I936), I5:2Ia. [One of Arthur Schopenhauer's first interpreters in China, Wang Guowei (1877-1927) wrote on aesthetics, philology, and literary theory.]

8. See Liu Dong, "Jinhua yu geming: Xiandai Zhongguo de sixiang pibian" 进化与革命 : 现代中国的思想丕变 [Evolution and revolution: A radical change in modern Chinese thought], Dushu, no. I2 (2016): 3-10.

9. Anthony Mario Ludovici, Nietzsche and Art (Boston: Luce, I9I2), 64-65. 
Io. [Samuel P. Huntington, The Clash of Civilizations and the Remaking of World Order (New York: Simon \& Schuster, 1996).]

II. [McNeill (I9I7-20I6) is the author, notably, of The Rise of the West: A History of the Human Community (1963; repr., Chicago: University of Chicago Press, I99I).]

I2. [Liu Dong refers to the new understanding of ancient civilizations that has emerged since the publication of McNeill's Rise of the West, in particular archaeological evidence of wide commercial networks and migration patterns linking Africa, the Mediterranean world, Northern Europe, Central Asia, and East Asia.]

13. Liu Dong, "On the Narration of the Past in China: An Outline," History of Humanities I (2016): 47-69, at 67. Original text: "Duiyu wangshi de Zhongguo jishu: Zuowei yizhong wenhua de lishixue” 对于往事的中国记述 : 作为一种文化的历史学, in Liu Dong, Ziyou yu chuantong 自由与传统 (Beijing: Peking University Press, 2015), 2 I3.

I4. Giambattista Vico, On the Most Ancient Wisdom of the Italians: Drawn Out from the Origins of the Latin Language (New Haven, CT: Yale University Press, 2010), 23-25.

I5. Hu Shi 胡适, “Shiyan zhuyi” 实验主义 [Pragmatism], in Hu Shi wenji 胡适文集 [Collected writings of Hu Shi], ed. Ouyang Zhesheng 欧阳哲生, I2 vols. (Beijing: Peking University Press, 2013), 2:206. [Hu Shi (189I-I962), educated at Cornell and Columbia, was one of the leading figures in the May Fourth Movement that advocated democratic reform, adoption of scientific culture, and the use of vernacular rather than classical Chinese in literary writing.]

I6. [The quoted fragments paraphrase the justification of the historian's mission by Sima Qian 司马迁 (ca. I45-ca. 86 BCE) in “Bao Ren An shu” 报任安书 [Reply to Ren An], as given in Ban Gu 班固, “Sima Qian zhuan” 司马迁传 [Biography of Sima Qian], chap. 62 in Han shu 汉书 [History of the former Han dynasty]. See Han shu, Io vols. (Beijing: Zhonghua shuju, I962), 9:2735.]

I7. [This saying, often attributed to Winston Churchill, Hermann Göring, and other notorious figures of the Second World War, is impossible to pin to any one person or party. The defeated at the end of that war decried the Nuremberg and Tokyo war crimes trials as "victors' justice." Variations on the theme are found in Friedrich Nietzsche, Walter Benjamin, George Orwell, Bertolt Brecht, and others.]

I8. [The first sentence is proverbial; the second comes from Zhuangzi Io, “Quqie” 胠笧 [Rifling trunks]. See Guo Qingfan 郭庆藩, ed., Zhuangzi jishi 庄子集释 (Beijing: Zhonghua shuju, I962), 350.] 
I9. Liu Dong, "The Unique Phenomenon of Writing by the Elderly" (unpublished manuscript, Tsinghua University, 2017).

20. Liu, "Unique Phenomenon of Writing by the Elderly."

2I. Peng Gang 彭刚, "Lishi jiyi yu lishi shuxie: Shixue lilun shiye xia de "jiyi de zhuanxiang””历史记忆与历史书写 : 史学理论视野下的“记忆的转向” [Historical memory and historiography: 'The memorial turn' in the field of historical theories], Shixueshi yanjiu, no. 2 (20I4): I-I 2, at 2-3.

22. Pierre Nora, ed., Realms of Memory: Conflicts and Divisions, trans. Lawrence D. Kritzman, 3 vols. (New York: Columbia University Press, I996), I:20.

23. [Kang Youwei (1858-1927) and Liang Qichao (1873-1929) were among the leading figures of the brief Reform Movement of 1898 that was put down by Empress Dowager Cixi (I835-I908) and her allies within the Manchu ruling clique. Chen Boda (I904-89), Mao's personal secretary and ghostwriter for many years and one of the "Gang of Four" blamed for the excesses of the Cultural Revolution, has left a memoir, “Chen Boda zuihou koushu huiji” 陈伯达最后口述回忆 (Chen Boda's last recollections, orally transmitted); an introduction may be found at http://marxistphilosophy.org/ChenBoda/I2060I/250.htm.]

24. [The four people mentioned, members of the "Lin Biao clique," were imprisoned after Lin Biao's fall in I97I.]

25. [Lin Biao (I907-7I) was a marshal in the People's Revolutionary Army, the only Vice Chairman of the Chinese Communist Party during the Cultural Revolution, and Mao's designated successor. After relations between Lin and Mao soured, Lin died in an air crash in Mongolia. Chinese accounts of the event claim that Lin had planned a failed coup against Mao. No international consensus on the matter has been reached. The last phases of the Cultural Revolution involved a nationwide campaign "criticizing Lin Biao and Confucius" together.]

26. Hu Shi, “Lun guoguxue: Da Mao Zishui xin” 论国故学 : 答毛子水信 [On the study of national history: A letter in reply to Mao Zishui], in Hu Shi wenji, 2:296. [In somewhat fuller context: "To systematize the ancient history of China is valuable for world scholarship, but not so important. . . All research is equal [from the point of view of truth]. To discover the ancient meaning of a character is no less a contribution than to discover a star."]

27. [Gu Jiegang 顾颉刚 (I893-I980) was the editor of the occasional periodical Gushibian 古史辨 (Debates on ancient history), which published essays, letters, and forum responses tending to argue that the Chinese Classics and traditional history were legends crafted to support the pretensions of different dynasties. A high school history textbook written by $\mathrm{Gu}$ in this skeptical vein was suppressed 
by the Guomindang government in I929. Gu's scholarly associates were known as the "Doubters of Antiquity." "Believers in Antiquity," never an organized movement, is a label concocted in the midst of the polemics aroused by Gu and his school.]

28. [The scholarship of Wang Guowei 王国维 (1877-I927) ranged from the poetics of vernacular fiction to the philosophy of Schopenhauer to the philology of bronze and oracle-bone inscriptions. One of the leading figures in the Chinese intellectual world, he astonished his contemporaries by drowning himself as an expression of loyalty to the Qing dynasty, by then sixteen years in the past. Among his students was Chen Yinque 陳寅恪, on whom see below.]

29. Wang Guowei, "Zuijin ersanshinian zhong Zhongguo xin faxian zhi xuewen” 最近二三十年中中国新发现之学问 [Newly discovered subjects of scholarship in the past two or three decades], in Wang Guowei wencun 王国维文存 (Nanjing: Jiangsu renmin chubanshe, 2014), 744.

30. [Jacob Burckhardt, Reflections on History, trans. Gottfried Dietze (Indianapolis: Liberty Classics, I979), 54.]

3I. Qian Mu 钱穆, “Preface," in Zhongguo xueshu tongyi 中国学术通义 [A survey of Chinese scholarship] (Taipei: Taiwan xuesheng shuju, I975), 5. [Qian Mu (I895-1990), a historian of Chinese thought and institutions, leaned toward a positive interpretation of traditional culture. On his biography, see Jerry Dennerline, Qian Mu and the World of Seven Mansions (New Haven, CT: Yale University Press, I988).]

32. Zhang Zai 张载 (I020-77), “Jingxue liku: Xue dayuan shang” 经学理窟: 学大原上, in Zhang Zai ji 张载集 (Beijing: Zhonghua shuju, I978), 279.

33. Zhang Zai, “Jingxue liku: Yili” 经学理窟: 义理, in Zhang Zai ji, 27 I.

34. Alexander Des Forges (Dai Shadi 戴沙迪), "Shuzi renwen yu keju wenxue jian de jingu qiguan” 数字人文与科举文学间的今古奇观 [Present and past wonders: Between digital humanities and literatures of imperial examination], Zhongguo xueshu 35 (2015): 385-97, at 393.

35. [On this event, the Google DeepMind Challenge Match of March 2016, see https://deepmind.com/research/alphago/alphago-korea.]

36. [Qian Zhongshu 钱锤书 (I9IO-88) was renowned for his short, pungent essays displaying an intimidating range of citations from many languages, usually attesting literary parallels between Chinese and European texts. A selection from his critical writings has been translated by Ronald Egan as Limited Views: Essays on Ideas and Letters (Cambridge, MA: Harvard University Asia Center, I998).] 
37. [An expression used by Wang Anshi 王安石 (I02I-86) to disparage the Spring and Autumn Chronicles. See Tuotuo 脫脫, ed., Song shi 宋史 [History of the Song dynasty] (Beijing: Zhonghua, I977), 30:I0550.]

38. Zhuangzi I9, "Yang sheng zhu" 养生主, trans. Burton Watson, in The Complete Works of Chuang Tzu (New York: Columbia University Press, I968), I45.

39. Qian $\mathrm{Mu}$, Guoxue xinlun 国史新论 [A new discussion of national history] (Beijing: Joint Publishing, 2005), I.

40. Qian Mu, Guoxue xinlun, 3.

4I. Sima Qian, "The Hereditary House of Confucius," chap. 47 of Records of the Grand Historian, in Shiji (Beijing: Zhonghua, I965), I943.

42. Compare Liu Dong, "On the Narration of the Past in China," 63-64.

43. Liu, "On the Narration of the Past in China," 55-56.

44. Wang Yongxing 王永兴, Chen Yinque xiansheng shixue shu lüe gao 陈寅恪先生史学 述略稿 (Beijing: Peking University Press, I998). [Chen Yinque 陳寅恪 (I890-I969), a scholar of exceptional linguistic range, was among the first to take advantage of the newly discovered polyglot Dunhuang manuscripts from Chinese central Asia in order to write a new history of the culturally eclectic institutions of the Sui (58I-6I8) and Tang (618-907) dynasties. His tomb inscription for Wang Guowei (on whom see Section VII) has become famous as a manifesto of academic inquiry, praising Wang's “independence of spirit and freedom of thought” (独立之精神，自由之思想).]

45. ["History is made in such a way that the ultimate result is invariably produced by the clash of many individual wills of which each in turn has been made what it is by a wide variety of living conditions; there are thus innumerable conflicting forces, an infinite number of parallelograms of forces, productive of one result-the historical event." Friedrich Engels, letter to Joseph Bloch (September 2I, I890), in Karl Marx and Friedrich Engels, Collected Works, 50 vols. (London: Lawrence \& Wishart, 200I), 49:35.] 